\title{
Appraisal of the Sport Facilities Maintenance Management Practices of Malaysian Stadium Corporations
}

\author{
Mohd Taib Harun ${ }^{1}$, Norlena Salamudin ${ }^{1} \&$ Hasnul Faizal Hushin ${ }^{2}$ \\ ${ }^{1}$ Faculty of Education, Universiti Kebangsaan Malaysia, Selangor, Malaysia \\ ${ }^{2}$ Universiti Teknologi MARA (UiTM), Shah Alam, Selangor, Malaysia \\ Correspondence: Mohd Taib Harun, Faculty of Education, Universiti Kebangsaan Malaysia, 43600 UKM Bangi, \\ Selangor, Malaysia. E-mail: mtaibharun@gmail.com
}

\author{
Received: August 1, 2013 Accepted: August 16, 2013 Online Published: August 30, 2013 \\ doi:10.5539/ass.v9n12p93 URL: http://dx.doi.org/10.5539/ass.v9n12p93
}

\begin{abstract}
This study is aimed to obtain important information related to maintenance management practices of public sports facilities managed by the Stadium Corporation in Malaysia. Important information such as key features, facility maintenance information and level of effectiveness is the main focus of the study. The finding of this study is part of an ongoing study, which focuses on the information of maintenance management carried out by Stadium Corporation agency. Survey questionnaires were distributed to 7 Stadium Corporation and involving 34 key personnel who are directly involved in the sports facilities maintenance management, such as general managers, managers, officers, engineers, assistant engineers and supervisors of sports facilities. The percentage of maintenance management effectiveness is calculated from the good practice of each main maintenance success factors. From the score of maintenance success factors, results showed that $85.3 \%$ of Stadium Corporation in Malaysia is rated moderately satisfactory, $2.9 \%$ excellent and $11.8 \%$ is at an unsatisfactory level. This study is expected to help provide important information that can help administrators understand the issues related to the maintenance management of sports facilities, thus helping to improve the level of sports facility maintenance management in Malaysia to greater heights.
\end{abstract}

Keywords: sports facilities, maintenance management

\section{Introduction}

Public sports facilities in Malaysia are part of government assets built with large allocations. Due to the nature and needs of each game, facility was built in such a way as outlined by international rules of the game. Sports facility was also built in every state and district in order to meet the government's aspiration to inculcate healthy life style to the community. Nevertheless facilities provided by the government should be well maintained in order to be harnessed and not to impede the government's efforts to encourage community sports and do physical activity due to unsafe and damaged sports facilities.

The issue of poor maintenance does not only involving sports facilities, but is a national problem plaguing management of government assets and all government-owned premises. This issue has been reprimanded by the Deputy Prime Minister in 2005 and now Prime Minister of Malaysia, Dato' Sri Najib Tun Abdul Razak with the firm conviction to no longer build any new sports facilities due to poor maintenance. Nevertheless the same issue continues to repeat these days as many incidents involving poor sports facility maintenance has caused the government to lose millions of dollars as a result of poor maintenance. Citing a number of press releases and Malaysia Auditor General's report on poor maintenance of sports facility includes Terengganu Stadium incident (2009), Terengganu Aquatic Complex (2006 \& 2011), Kedah Aquatic Complex (2009), Langkawi International Shooting Range Malaysia (2009), "Rakyat" Velodrome (2011) and many more sports facilities throughout Malaysia.

Based on the Malaysia Plan starting from 1966 to present, various types of sport facilities were built throughout the country. Each facility constructed is based on commitment and policies of the Malaysian government to promote the importance of unity through sports activities for the community and as well as to promote healthy community. The formulation of the National Sports Policy (NSP), which became the national sports development blueprint created in 1988 is a roadmap to strengthening the government's commitment and dedication to sports 
development as translated in each Malaysia Plan, where sports facilities is an important aspect that catalyst encouragement to the community, to support the development of sports for all and high performance sports.

Planning and construction of sports facilities in Malaysia rapidly began in the first Malaysia Plan to the present. Various types of small and big scale sports facilities are built in each term. Rapid increase in the construction of sports facilities began during fifth Malaysian Plan (1986-1990) and from 1990 to 2000 alone the Government of Malaysia has 12 football stadiums with a seating capacity of 30,000 people (Maassoumeh Barghchi et al., 2011). The Star (2005) shows that there are 8,261 sports facilities built in Malaysia. A total of 619 facilities are managed and operated by the Ministry of Youth and Sports and the remaining 7,642 are under the management of the State Government and Local Authority (LA).

Arguably, sports facilities situation in Malaysia has been unsatisfactory in terms of maintenance and this resulted in more funds are needed for major repair, replacement or even builds new sports facilities. The facility was built with millions of dollars, from an economic standpoint is seen not able to generate enough profits resulting from failure of maintenance aspects which have reduced the productivity of the sports facility. This situation happened to Shah Alam Stadium which was only able to generate a profit of RM3 million a year compared to an annual maintenance cost of RM 5 million (The Star, 2007). Failure of equipment and damaged facilities, indirectly increase operating costs and reduce revenue gains or income to the organization (Mitchel et al., 2002). Based on previous studies researchers agree that effective maintenance can improve the performance of facility operations and in time generate profits for the organization.

This study was aimed to identify the sports facilities maintenance effectiveness managed by the Stadium Corporation agency in Malaysia. Through this study, outcomes and findings can be guided to the relevant agencies to improve existing shortcomings and at the same time can be used as a standard measurement for all public facilities in Malaysia. Among the main objectives of the study are to 1) identify the effectiveness level of the maintenance management of sports facilities managed by Stadium Corporation agency in Malaysia and 2) identify the characteristic related to maintenance management of sports facilities managed by Stadium Corporation agency in Malaysia.

\section{Methodology}

A survey was conducted which seeks to describe and explain the maintenance management effectiveness of sports facilities in Malaysia. Maintenance Effectiveness questionnaire by Cholasuke et.al (2004) and Mohd Saberi (2007) is used in this study. The study takes into account the key elements for effective maintenance that have been identified by practitioners and professionals in the field of maintenance. 9 major elements has been identified as an important elements of maintenance management effectiveness factor such as 1) policy deployment and organization, 2) maintenance approach, 3) task planning and scheduling tasks, 4) information management and CMMS, 5) management of spare parts, 6) human resource management, 7) financial aspect, 8) continuous improvement and 9) maintenance contract management.

Maintenance Management effectiveness questionnaires were distributed to seven (7) general managers of the Stadium Corporation in Malaysia. Cover letters and questionnaires were addressed directly via postal to all general managers of 7 Stadium Corporation in Malaysia. Prior to this, a pilot study has been carried out to see the feasibility and acceptance of important inputs for this survey. Data received from the pilot study was analyzed and the 36 items showed a reliability factor of 0.833 .

On the aspect of sample selection, the researcher chooses a selection of subjects from the population as the respondent, and in this context the study population consists and focuses specifically on the 7 Stadium Corporation agencies, involving 34 respondents overall. Justification for selection of this population is based on the modus operandi of sports facilities management in Malaysia which is either under the responsibility of the local authorities or Stadium Corporation agencies. Therefore, purposive sampling was used to select respondents in this study. Those involved as respondents were directly responsible for their respective sports facilities maintenance.

\section{Result}

Thirty four (34) respondents, from six (6) Stadium Corporation under the state government agency and one (1) from the federal government agency were involved in the survey. Based on these findings, respondents who hold substantive post in engineering is only $48 \%$ where $5.9 \%$ is the Engineer, Assistant Engineer $20.6 \%$ and $23.5 \%$ is Technical Assistant / Technician and the remaining 38.2\% consists of Administration, Sports 5.9\%, while Others $5.9 \%$.

Academic background information on the Stadium Corporation personnel indicates only $2.9 \%$ have Masters 
degree, 17.6\% have Bachelors degree, 38.2\% were Diploma holders, 14.7\% has Polytechnic Certificate, 20.6\% were high school graduates (Malaysia Certificate of Education) and 5.9\% has Malaysia Higher School Certificate (MHSC). A cross tabulation analysis between respondents' background and academic qualifications showed that respondents with engineering degree was low (5.9\%) and those with Diploma and Polytechnic Certificate were $38.2 \%$ and $14.7 \%$ respectively. While respondent who holds a Diploma (Technical) in Civil Engineering is $8.8 \%$ and $20.6 \%$ in Electrical Engineering. Respondent with Polytechnic Certificate in Civil Engineering was 2.9\%, Electrical Engineering 2.9\% and 8.8\% in Mechanical Engineering. Based on this information, it was noted that the $5.9 \%$ respondent with a degree are mainly from Electrical Engineering and none from Civil and Mechanical engineering fields.

A cross tabulation analysis between professional and academic background held by respondents holding the post of Manager or General Manager is from Finance background $(n=1)$ and others $(n=2)$. For Assistant Managers and Assistant General Managers also have a similar background in General Management degree $(\mathrm{n}=1)$, and other $(\mathrm{n}=1)(5.9 \%)$. None has engineering or facility management background. The rest of the support personnel of the sports facilities that rank as Administrative Assistant 23.5\% $(\mathrm{n}=7)$, other $5.9 \%(\mathrm{n}=2)$ and Agriculture $2.9 \%(\mathrm{n}=1)$.

With regards to work experience of the respondent, more than half of the respondents have been working for less than 5 years $(52.9 \%)$. The remaining $40.6 \%$ have more than 5 years of work experience and $5.9 \%$ of the respondents have more than 20 years of experience. Results also showed that majority of the respondents have a satisfactory working experience with Stadium Corporation. Referring to their responsibilities in managing number of public sports facilities, $70.6 \%$ of the respondent managed about 5 to 20 types of sports facilities ranging from field, courts, complexes and stadiums, whereas $29.4 \%$ managed less than 5 facilities. The age distribution of sports facilities managed by Stadium Corporations between 5 to 20 years $(76.5 \%)$ and aged 20years and above $(23.5 \%)$.

With respect to respondent maintenance strategies, $14.7 \%(\mathrm{n}=5)$ of the respondent prefer insourcing all their maintenance services and rated their current practice as unsatisfactory and none of those that outsource all their maintenance services rated their systems as excellent. However, the majority of those who combined insourcing with partial outsourcing strategies rated their system as satisfactory $(n=17)$.

A question was designed to capture respondent perception towards their sports facilities maintenance effectiveness and results showed 22 respondents agreed (64.7\%) that the level of maintenance management is satisfactory, 12 respondents (35.3\%) agreed the level of maintenance management is excellent, and none of the respondents stated as less effective. The percentage of maintenance management effectiveness is calculated from the good practice of each main maintenance success factors. The perception percentage are then compared with the actual total score of maintenance success factors and the results showed that $85.3 \%$ of respondents rated moderately satisfactory, $2.9 \%$ excellent and $11.8 \%$ said the level of effectiveness is at an unsatisfactory level.

\section{Discussion}

Initial assumption of this study, assumes that the maintenance management of sports facilities managed by the Stadium Corporation in Malaysia is excellent. Analysis of the findings showed $64.7 \%$ of the respondents indicated the effectiveness of maintenance management in each sport facility reaches a satisfactory level and $35.3 \%$ said to be in excellent level. Taking into account the size of this perception, the level of maintenance for Stadium Corporation sports facilities in Malaysia is something that we can be proud of. From the findings showed that the actual level of maintenance management is in satisfactory conditions. However if based on their compliance with key elements of effective maintenance management, 97.8\% of the Stadium Corporation agencies in Malaysia reported a normal or weak level of effectiveness, and has not yet reached a level that is very effective and successful. The Stadium Corporation who maintains the sports facilities need to take the initiative and more effective approach to ensure the effectiveness of maintenance management at each facility, and meets the outstanding criteria that have been outlined. This finding is also in line with other research by Mohd Saberi (2007) and Ashola et al. (2010) that the level of maintenance for other type of government facilities and universities complexes in Malaysia are also in a satisfactory level.

Some revealing insight found several Stadium Corporation did not have any engineers or specific technical personnel and all maintenance management responsibilities is carried out by the Manager or the General Manager of the Stadium Corporation. Based on information obtained 5 out of 7 agencies involved in the study do not have any civil engineers assigned to maintenance work. The information is also an important finding based on the theory those who are involved in the maintenance and facility management should have personnel with at least a background in Engineering or at best in facility or asset Management. This situation showed deficiencies 
in the structure of the organization of the Stadium Corporation in Malaysia which need to be improved. It is suggested that this personnel need to be trained or gain additional qualifications in facility management and related building maintenance. Approval of professional competence is needed, so that no untoward incidences occurred in sports facilities in Malaysia. However, at this time, no evidence showed that this proposal is being considered critical.

Results also shows that the distribution of positions of large scale Stadium Corporation has more technical background engineering personnel compared to smaller Stadium Corporation and any matters relating to maintenance is managed by the General Manager or the administrative personnel of the sports facilities. The low number of experienced maintenance personnel in most sports facilities lead to maintenance work being done focuses only on housekeeping activities and routine maintenance activities. This will result in the maintenance personnel being demotivated due to high work-load and low manpower. Experienced personnel are an important asset to the Stadium Corporation and have an impact on the effectiveness of maintenance. Majority of the Stadium Corporation does not have enough maintenance personnel and they should take necessary action to train and equip the existing personnel with maintenance skills through in-house and ongoing training. This training would help employees to be more motivated in performing their daily tasks (Cholasuke, 2004).

This study is important as it provides a picture of maintenance effectiveness in sports facilities managed by Stadium Corporation from the perspective of key personnel in maintenance and management of the agency. Findings of this survey revealed that the majority of the Stadium Corporation in Malaysia prefers the combine approach of insource and partial outsources. Majority of the Stadium Corporation combined insource and partial outsource rated their system as satisfactory. This is the strategies that are being used by Stadium Corporation agency where most of them apply insourcing and limit the outsourcing maintenance work only to specialist maintenance work. Most state Stadium Corporation face problems of inadequate maintenance budget and they apply the 'only urgent attention' strategy to help them control and use of financial resources. On the positive site this is a good approach but it is also an issue where the in-house maintenance organization personnel are less competent and inactive because of redundancy of maintenance work (Ashola et al., 2011). Only 1 Stadium Corporation use outsource strategy although there is a suggestion from the government to rely on their own resources but still the strategies on outsourcing maintenance services received substantial criticism and based on Auditor General Report in 2010 and 2011 the agency failed to monitor the progress work on certain outsource maintenance job.

The effect of poor maintenance may limit community participation in sports activities as a result of lack of sports facilities that are safe and ready to be used. Several studies carried out showed that the major involvement of the community in sport and physical activity are largely driven by the preparation and sports facilities that are easily accessible and well maintained (Richard et al., 2010: Lisa, 2006: Chao, 2006: Rhodes, 2007). If sports facilities provided did not function due to poor maintenance, then it will lead to a more severe impact not only on the financial state but a negative impact on community development and social change.

Failure of equipment and damaged facilities, indirectly increase operating costs and reduce revenue gains or income to the organization (Tsang, 2002). Based on previous studies researchers agree that effective maintenance can improve the performance of facility operations and in time generate profits for the organization. Maintenance of current best practice in the maintenance management can be applied for the sports facilities maintenance such as Reliability Centered Maintenance and Total Productive Maintenance. Both of these approaches emphasize the concepts and methods of maintenance as systematic, efficient and effective with low cost. Meanwhile the usage of computerized maintenance management system (CMMS) is an essential tool in terms of flow and control of information for maintenance management facilities. This concept can be applied in the maintenance of the sports facilities to be more efficient and competitive. Department heads and managers must manage sport facilities in accordance with procedures and proper maintenance standards, comply with all laws and regulations as well as appreciate the best practices.

\section{Proposed Sport Facilities Maintenance Management Model}

Basically this model is based on the formation of empirical findings from a major research and theories related to maintenance management and supported by discussions with experts in the field of facility maintenance management. Sports Facility Maintenance Management Effectiveness Measurement Model is a combined concept of Facility Management and Performance Measurement formed and backed by management theories (Henry Fayol, 1920), Organizational Theory (Max Weber, 1947) and the Expectations theory (Victor Vroom, 1964). This model unites elements for effective maintenance management, the concept of facility management in each phase of systems planning, organizing, implementing, leading and control. In each phases of management a 
set of criteria and management activities are assigned to be performed to ensure the effectiveness of maintenance management can be archived.

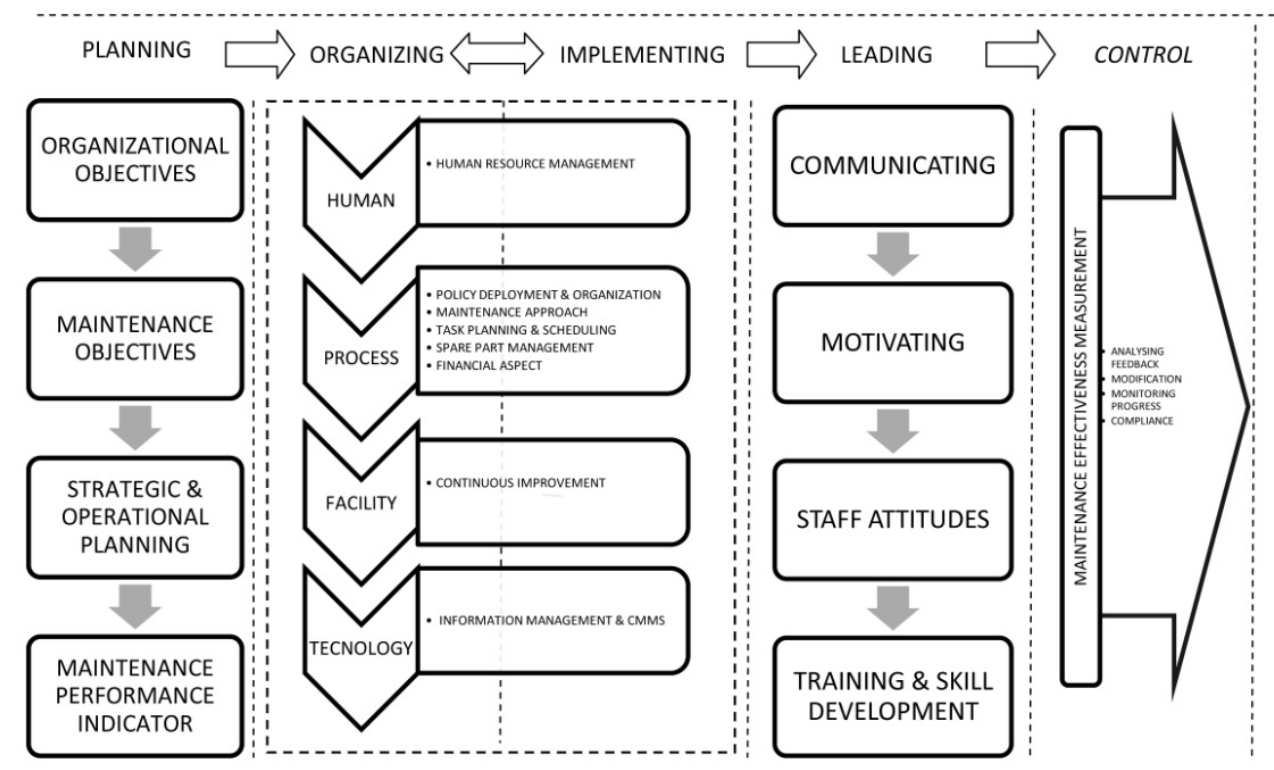

Figure 1. Sports facilities maintenance management model

In this way, the maintenance will receive the attention it deserves in the top management level. Therefore, it would not be seen as purely tactical operations and as a burden as it used to be. Stadium Corporation must consider and accept maintenance as a factor of production that requires strategic attention as other resources in an organization.

\section{References}

Aditya Parida, U. K. (2006). Maintenance Performance Measurement (MPM): Issues and Challenges. Journal of Quality in Maintenance Engineering, 12(3), 239-251. http://dx.doi.org/10.1108/13552510610685084

Albert, H. C., Tsang, A. K. S. J., \& Kolodny, H. (1999). Measuring Maintenance Performance: A Holistic Approach. International Journal of Operation and Production Management, 19(7), 661-715.

Chuenusa Cholasuke, R. B., \& Antony, J. (2004). The Status of Maintenance Management in UK Manufacturing Organizations: Results From A Pilot Survey. Journal of Quality in Maintenance Engineering, 10(1), 5-15. http://dx.doi.org/10.1108/13552510410526820

Deris, M. S. M. (2007). Public Sector Facility Management Maintenance Effectiveness in Federal Territory of Kuala Lumpur. Unpublished Thesis. Universiti Teknologi Malaysia.

Hackman Hon Yin Lee, D. S. (2008). Overview of Maintenance Strategy, Acceptable Maintenance Standard and Resources from a Building Maintenance Operation Perspective. Journal of Building Appraisal, 4(4), 269-278.

Hackman Hon Yin Lee, D. S. (2009). Strategic and Operational Factors Influence on the Management of Building Maintenance Operation Process in Sports and Leisure Facilities, Hong Kong. Journal of Retail and Leisure Property, 8(1), 25-37. http://dx.doi.org/10.1057/rlp.2008.29

Hall, S. (2010). Impact of Facility Maintenance on Campus Recreational Sports Departments at Public Universities in the United States. Recreational Sports Journal, 34, 103-111.

Lateef, O. A. A., Khamidi, M. F., \& Idrus, A. (2010). Appraisal of the Building Maintenance Management Practices of Malaysian Universities. Journal of Building Appraisal, 3/4(6), 261-275.

Liu, Y. D. (2009). Implementing and Evaluating Performance Measurement Initiative in Public Leisure Facilities: An Action Research. Syst Pract Action Res, 22, 15-30. http://dx.doi.org/10.1007/s11213-008-9103-y

M.Khairul, A. (2011). Cycling: Velodrom Rakyat Close. New Straits Time. 
Maassoumeh Barghchi, D. O., \& Aman, M. S. (2009). Sports Facilities and Sustainable Development. Sustainability in the Built Environment. University of Plymouth, UK. Association of Construction Management

Maassoumeh Barghchi, D. O., Mohamad Salleh Aman, S. K, \& Huat Bujang, B. K. (2010). Exploratory Research on Sports Facilities Construction In Malaysia. Australian Journal of Basic and Applied Sciences, 4(10), 5326-5331.

Manuel, G. L. (2010). Perceived Barriers by University Students in the Practice of Physical Activities. Journal of Sports Science and Medicine, 9, 374-381.

National Audit Department of Malaysia. (2003). Activity Reports and Special Studies Agency /Department of State 2003.

National Audit Department of Malaysia. (2009). Auditor General's Report: Activities Ministries/ Departments and the Management of the Federal Government of Malaysia.

National Audit Department of Malaysia. (2011). Auditor General's Report 2011: Federal Statutory Bodies.

Richard, G., Prins, P. V. E., Saskia, J., Te Velde, A. T., Frank, J., Van Lenthe, N. I., ... Oenema, A. (2010). Availability of Sports Facilities as Moderator of the Intention-Sports Participation Relationship among Adolescents. Health Education Research, 25(3), 489-597. http://dx.doi.org/10.1093/her/cyq024

Torgeir Limstrand, N. J. R. (2008). Young People's Use of Sports Facilities: A Norwegian Study on Physical Activity. Scandinavian Journal of Public Health, 36(5), $452-459$. http://dx.doi.org/10.1177/1403494807088455

Tsang, A. H. C. (2002). Strategic Dimension of Maintenance Management. Journal of Quality in Maintenance Engineering, 8(1), 7-39. http://dx.doi.org/10.1108/13552510210420577

\section{Copyrights}

Copyright for this article is retained by the author(s), with first publication rights granted to the journal.

This is an open-access article distributed under the terms and conditions of the Creative Commons Attribution license (http://creativecommons.org/licenses/by/3.0/). 